\title{
Perceptographic code in visual culture ${ }^{1}$
}

\author{
Leonid Tchertov \\ Dept. of Philosophy, Saint-Petersburg State University, \\ Mendeleevskaja line 5, St. Petersburg 199034, Russia \\ e-mail: tcher@LC9661.spb.edu
}

\begin{abstract}
Visual culture can be considered from semiotic point of view as a system of visual codes. Several of them have natural routs. So the perceptual code is formed already on biological level mediating translation of sensory data into perceptual images of the spatial world. The means of natural perceptual code are transformed in culture, where they are involved in communication by depictions. The depiction on the flat performs the function of a "perceptogram", which, on one hand, is an external record of an internal perceptual image or an idea, and, on the other hand, serves as a program for a spectator's visual perception. The means of this "perceptography" form an artificial code, which is, on the contrary to the perceptual code, communicative, deliberately used and transformed in various ways at different periods of time in diverse kinds of practical and artistic activity. Not all perceptograms become pieces of art, but all history of pictorial arts can be considered as a process of development and mastering with the different versions of this perceptographic code. The changes of this code in visual culture are connected with the intrinsic development of "vision forms" as well with invention of external means of communication.
\end{abstract}

\section{Visual culture and perceptual code}

Human, unlike other animals, can not only receive optical data, but also deliberately produce them, creating depictions. The ability to produce and reproduce depictions is conditioned, besides natural system of eyesight, by culturally elaborated skills, and it depends on both

This paper is based on the report presented at VIII Congress of IASS in Lyon, France (2004). Its draft has been published in Amsterdam International Electronic Journal for Cultural Narratology (http://cf.hum.uva.nl/narratology/tchertov.htm). 
external technical means known in definite culture and internal ways of operating visual images. There is a connection between technical and psychical means of treating optical data, in particular, some internal "forms of vision" depend on external "forms of communication" of visual messages, which are at disposal of interacting subjects.

A system of technical and mental means, worked out historically for creating, transmission and receiving of optical information and cultivated by an individual or a collective, can be defined as visual culture of these subjects. Like any other culture, the visual one can be considered from semiotic point of view — as a system of both particular visual codes intended mostly for spatial channel of information connection, and optically presented texts, created and interpreted by these codes.

The visual codes include sign and signal systems with diverse psychological and semiotic mechanisms and to different extent depend on natural and cultural factors. The visual culture not only develops a number of artificially created sign systems, but also transforms several codes, which have natural routes and are formed on biological level as means of adaptation to the changes of surroundings.

It is possible to consider the perceptual code as one of these natural index-signal systems, regulating translation of optical data from visual field into a perceptive image of things unfolding in visible world (using the terms suggested in Gibson 1950: Ch. III). By means of this code, a mosaic of light and dark spots, which is formed on the sensory level, transforms on the perceptual level into stereometric picture of spatial situation.

These two levels of vision differ from each other by their structural qualities. The structure of visual field is correlated with the body scheme by relations "left-right", "high-low", "centre-periphery", etc. These relations form a stabile "framework" of visual field - in contrast to its unstable "filling" with changeable configurations of light and colour spots. Unlike this sensory level, the level of "visible world" contains the perceptive images of spatial forms, presented as opposed to the body of the seeing subject and separated from each other by "empty" inter-objective space. These images have a quality of constancy - being independent of unimportant variations of distance, visual angle, lighting, colour tints and other features of the 
perceived object, which remains an invariant of variable conditions of seeing and "filling" of visual field.

Both sensory and perceptual (in the narrow sense) levels of vision are not reflected in common perception. The last is the perception in the broad sense, which includes as an obligatory component one more level of vision, connected with recognition of objects of the visible world as representatives of some class or cognitive category (as it is treated, for example in Bruner 1973: 7ff.). These categories are invariants already in relation to variations of object forms and their perceptive images, which can be identified with the same visual scheme. On this "apperceptual" level of vision these objects are identified by a subject as something or somebody meaningful - as a useful tool, as a civil servant, etc.

The perception of the "pure world of volumetric forms" and even more the reception of the "pure world of light and colour spots" are abstractions from the "world of meaningful objects". They are not typical for everyday vision and need a skill of "analytical introspection", getting by special education and being always incomplete. In the "natural" process of seeing transits from sensory to the perceptual and then - to the apperceptual levels of vision occur unconsciously and are the parts of the whole cognitive action. But in theoretical analysis these levels must be distinguished, - as well as the visual codes serving for the translation and transformation of optical data between them. There are, particularly, the codes of recognition, which mediate the processes of visual categorization of recognizable things and as semiotic systems are very different from the perceptual code.

Unlike them the perceptual code mediates the transit from the field of light and colour spots grasped on sensory level to the world of volumetric forms and their spatial relations developing in a perceptive image of visible space. In its system the difference between these two levels of vision reveals as the difference between the plane of expression and the plane of contents: the first is formed by relations between the parts of visual field with different light and colour qualities, and the second is constructed as a result of their unconscious interpretation on perceptual level as images of some external objects. 


\section{Perceptography as a communicative version of the perceptual code}

This naturally formed perceptual code is converted by human activity in its cultural versions, which can mediate not only the subject-object information connections but also inter-subject communication as well. Cultural modifications of the perceptual code give the possibility of creating and perceiving depictions as such artificial means of objects representation and communication between subjects, which stimulate visual perception of things absent in front of the spectator. The elements and structures of natural perceptual code are transformed in creating of depictions as communicative means. They are reflected and exteriorized, taken out and replaced by some visible substitutes. Psychical means of seeing are substituted by some physical elements, which are visible themselves. These visible spots and lines are created as if they were a projection on a plane of heterogeneous structure of colour feelings formed (or as if they were formed) in a visual field of a painter. Unlike volumetric sculpture, painted surface does not directly fix a constant perceptive image of objects independent of the point of view, the lightness, etc., but definite conditions of their appearance and a particular spots configuration in visual field. In a similar way the constant "regular field" forming as a rule a rectangular frame of depiction (see Schapiro 1994) becomes a "projection" of this visual field itself with its stable structure of relations "top-bottom", "leftright", "centre-periphery", etc. (cf. an idea of "organs projection", enveloped in Kapp 1877).

The "picture plane" is interpreted usually not as this projection of internal visual feelings from subject's mind onto an external surface, but as the projection of depicted spatial objects onto a plane (see, in particular Sedgwick 1980: 38-40). However, these objects can be received only because the flat of depiction serves as artificially created optical stimulus of their perception, and reproduces rather their "form of expression" on subject, than a "form of being" (according to Hildebrand's distinction of "Ausdrucksform" and "Daseinsform" see Hildebrand 1988: 133, 212).

A picture is treated at least since the Renaissance Age (by Alberti, Leonardo, etc.) as a "transparent surface", — not as a wall or a board, but as a window, which is looked through, and even lat. perspectiva was translated by Dürer as "seeing through" ("Durchsehen") — (see 
Panofsky 1998: 664, 716-717). In a perspective depiction configuration of spots and lines on a pictorial surface functions not as a "distant", but as a "proximal" stimulus. They perform the function of sensory data that are not independent elements of the depicted picture, like colour feelings in visual field usually are not independent objects drawing attention. Both of them are something looked through in the acts of perception of the depicted world, but not something looked at. If the look is directed not through but at the pictorial surface itself, the picture "returns" in a row of other things coexisting with it in common space. Thereby, the picture can be perceived both - as a single object of perception and as a means of perception of something else. Therefore the picture on the flat surface is a "paradoxical" object with "double space": it can be perceived, but can show something other instead of itself; it exists in the real space, but can open for sight another space filled with objects, which are absent in reality in front of the spectator (cf. Gibson 1979: Ch. 15; Gregory 1970: Ch. 2; Hartmann 1953: 98-99). These two spaces are co-related, correspondingly, as plane of expression and plane of contents in the sign constructions, and they are connected with each other even more, then two sides of a paper sheet, from famous comparison of bilateral signs suggested by F. de Saussure: they belong to one the same side only in different wais perceived.

From semiotic point of view a configuration of spots and lines stimulating perception of absent objects can be considered not as a single sign, but as a set of "sense-distinctive" relations forming together a visual-spatial text of particular kind. The word text originates from lat. textus as well as the word textile that allows to see its relationship to texture of a woven Gobelin and even of a painted canvas. However, neither natural texture nor created strokes themselves form the visual text of such type, but the relations of lines and colours, which are connected functionally with the processes of picture perception. Such visual-spatial text functions as a "perceptogram", which, on one hand is an external record of perception or "internal drawing" formed in artist's mind, and on the other hand, is a program guiding the visual perception of a beholder. Correspondingly, it acts expressively regarding to the creator and impressively in relation to the spectator, and only by this condition it performs also a representative function relating perceptive image each of them to an 
external referent (cf. "Organon Modell" of semiotic functions suggested in Bühler 1934: 28).

As a spatial text of a particular type, the perceptogram has a space, which is "divided" into both the depicting and depicted ones. They form in the perceptographic text, correspondingly, the "plane of expression" constructed by a surface covered with some colour or black-and-white spots, and the "plane of contents", where they are interpreted as a space of depicted objects. This double space of the picture supposes its double vision by "reading" as a text: its plane of expression is accepted on the sensory level of the "visual field", whereas the plane of contents is built on the perceptual level of the "visible world". So the developing of the plane of contents not on conceptual, but on the perceptual level is the other main peculiarity of perceptographic text.

Like any other text, the perceptogram can be replicated as far as its semiotic means are reproducible. These means are heterogeneous and belong to different types. There are certainly some structures in the pictures, which reveal an iconicity regarding to represented objects rather the iconicity of their quantitative relations (proportionality of linear sets, colour relationships, etc.), than of their "qualities" fixed by words (a "green" grass can be painted without a green paint only by precisely selected set of colour relations - as, especially, Camille Corot and Impressionists have shown). However, the painted surface as well as its meaningful parts cannot be reduced to "iconic signs" of depicted objects and often have few common with them in physical or geometrical qualities. Qualification of a picture as an "iconic sign" is based, as a rule, on the recognition of the depicted objects and on the establishing of their common features. In this case an iconicity of the picture can be not more, than that of the visual scheme used for the categorization of recognizable objects. Peircean concept of iconic sign allows to consider depictions as the means of representation and communication and thereby fix their semiotic functions. But it is not enough for distinction of various ways of depictions and their structural differentiation. If, for example, diverse photos, pictures, sculptures or roentgenograms of the same statesman are in equal way his "iconic signs", this concept does not give much to differentiation of these types of depictions and to explanation of their influence the beholder. Moreover, application of this concept does not explain some specific features of graphic (creating on a flat) depictions. The 
picture - treated in the broad sense, as a surface, which is covered with some spots and which shows something other except itself (cf. Gibson 1979: Ch. 15; Gibson 1980: xi), - cannot in principle be limited with such "iconic signs". Indeed, according to definition, the last represents their denotatum due to similarity or likeness with it, whereas the flat depiction, on the contrary, must be unlike the depicted volumetric object in order to look like it. Particularly, the rules of linear perspective prescribe deviation from geometric identity (congruence) between configuration of lines on the depicting plane and the depicted form of its spatial original. These rules demand, for example, to depict parallel lines as converged in a point, square - as an irregular quadrangle, circle - as an oval, etc. Influence of depictions on subject's perception becomes in these cases more important than their identity with a depicted object. The approach to the depiction as to an iconic sign does not clear these "deformations", because they belong to semiotic means of other types. In regard to represented object these means are indexes, which differ from it, but allow subject, who "reads" them as a visual text, to grasp its form and spatial situation, whereas regarding to this subject they are signals stimulating, more or less forced, defined perceptive actions construction in his mind a perceptive image of the depicted world. Thereby the perceptogram allows to represent something as if it would be presented to a subject, and it is possible due to the ability to create optical conditions of its perception, and to stimulate appearance of its spatial image in the mind of subject, rather than by similarity to something depicted.

Despite the index-signal means of such perceptography are derivative from perceptual code, they can be distinguished as an autonomous group and considered as a special perceptographic code. As an external artificial modification of the perceptual code it mediates not intra-subjective processes of cognition, but inter-subjective processes of communication. Its semiotic means differ from the means of the naturally formed and unconsciously used perceptual code, because they are selected as results of reflection of some sensory structures in processes of inter-subjective communication by depictions, and then transmitted in a cultural tradition.

For communication by means of depictions some features of individual images have to be translated into external means understandable for other subjects. Although lines and spots painted on the 
flat surface are based on the structure of the naturally formed sensory pattern, their selection is connected with culturally accepted norms and ways of depiction. These norms can prescribe to use, for example, definite "alphabet" of colours and several geometrical figures or more complex schemes as means of visual analysis.

This is the reason of such great difference between the ability of seeing a depicted in a depiction, and the reversal ability to translate percept into a depiction on a plane. The former can be based on natural system of perceptual code and is available in early childhood, whereas the skill of graphic depiction needs mastering of worked out culturally means of perceptography, and it requires long years of learning. It is an education rather of the eye and the mind than of the hand - the development of an ability to analyse visible form and select some linear and colour relations, which direct the formation of definite perceptive image. In other words learning to draw and getting a skill to create depictions is mastering index-signal means of perceptography.

The difference of this mastering between the creator and spectator does not mean that the last preserves a vision independent on any cultural influence. All people obtain in culture some ways of vision and interpretation, but these ways can be determinate by practical purposes and not connected with the depicting activity. However the qualified perception of depictions, created by different means of perceptography, demands to develop an ability to "read" them on the "visual language" used for their creation. But even without mastering the perceptographic code the spectator can as a rule see something depicted on a figurative picture using only "natural" perceptual code and the codes of recognition, whereas the creator of the depiction cannot in principle do without any means of perceptography.

Unlike naturally appeared perceptual code, the semiotic system of perceptographic code depends on definite visual culture much more. The means of perceptography are elaborated in different historical periods, different kinds of art or in various forms of everyday life, and they are coordinated with diverse cultural norms and ways of vision. Thereby diverse cultural versions of perceptographic code appear: in one case the role of main representative means is performed by linear contours, in other cases - by colour spots, etc. It is notable, that Heinrich Wölfflin, introducing the distinction between linear and painting "forms of vision" or "forms of representation" 
("Anschauungsformen" or "Darstellungsformen"), spoke about them as about "different languages" affording to express everything by their own means (see Wölfflin 1956: 22). Each of these "forms of vision" can be considered semiotically as a special way of creating and "reading" of visual image determined by the visual culture, particularly — as a special set of perceptographic means, used in this culture for constructing perceptive images of depicted objects.

At the same time dependence of these perceptographic means on culturally determined choice does not turn them into the fully conventional signs (as it was supposed by Goodman 1968). This turning occurs only if the conventional interpretation fully displaces the perceptual one, as it is performed, for example, in ideographic or phonetic writing. But in case of perceptography its means preserve some iconic features and are motivated by possibilities of the natural perceptual code. The visual culture only picks out within its framework some favorable elements and structures and develops by creators and spectators an ability to be limited by these means for building the perceptive image of the depicted object.

\section{Specific features of perceptographic code}

As a semiotic system the perceptographic code has specific features, which reveal themselves especially in comparison with the verbal language system. So, the syntax of perceptograms has the essential structural differences from sign constructions, like verbal texts. If the last ones are built as linearly ordered chains of discrete signs in irreversible succession, in case of perceptography the meaningful space cannot in principle be limited by the one-dimensional order of elements, and is always two-dimensional. Unlike the space of written text, the space of a perceptogram is reversible, because supposes in different dimensions both "direct" and "return" movements of the "reading" look. This space is often also continual as far as it does not demand abrupt jumps between meaningful or sense-distinctive units - in contrast to even continually written letters, which presume separation from each other. Like discreteness of writing, the continuality of the perceptographic text is rather a characteristic of semiotic "form" than of "substance" of its expression plane, because the qualities of physical bearers in both cases are of no importance. 
If the discreteness of successive units in verbal language reveals itself in the "principle of alphabet", the continual flowing of sensedistinctive shades of colours or tones corresponds to another principle, which can be called a "principle of palette". Like the palette gives the field for mixing of a number of ready paints, the perceptographic code as a system of optical means gives a possibility to exceed the limits of several standard units but to use the whole three-dimensional and continual "space of colours" with the fluent transits between different nuances of the spectrum as well as between their more or less dark and more or less pure shades. The "principle of palette" is valid also for lineal configurations, which can continually vary in two-dimensional depicting space, preserving the representative function in each of its fragments.

These syntactic features are connected with the specific semantics of the perceptographic code. As it was already mentioned, its plane of contents develops on the perceptual level, which permits to construct an image of the three-dimensional and continual space; this continuity of the depicted space motivates the same quality of the depicting plane. The relations between the plane of expression and the plane of contents in the perceptographic code differ from semantic relations in verbal language and similar systems of conventional signs by their non-significative way of representation. Instead of signs "vocabulary" with fixed meanings this code disposes a set of linear and colour indexes of different types, which meaning is not fixed without any context, but is obtained in the system of relations with other indexes. So, a configuration of drawn lines forms a net of connections, which does not signify directly "what" is depicted, but shows "where" the borders of the depicted figures, their coverings and intersections, etc. are situated, and only the resulting shape can be recognized. In a similar way a pattern of colour spots painted on a flat, arranges a system of contrasts and nuances between dark and light, bright and $\mathrm{dim}$, etc. These relations form a set of indexes of the depicted world and of signals directing movements of the look in perceptive acts.

Comparing such structure of perceptographic code with organization of linguistic systems, it is possible to say, that perceptography has some features not of "lexical", but of "grammatical" type of languages, as they were distinguished by F. de Saussure (see Saussure 1972: 183). In the languages of grammatical type the motivated rules of constructing prevail over a set of conventional signs. The same 
regards to the perceptographic code, where, for example, the linear perspective serves as a system of grammatical rules regulating construction of linear relations, but not as a set of lines and outlines with a "ready" meaning, - as well as a set of relations between colour spots in the system of lights and shadows is more important for creating of a perceptive image of the depicted situation, than any of these spots separated from each other. (Structural point of view, according to which the whole system of representative means is more important, than single elements, is valid equally for pictorial representation - as it has been shown theoretically by Gestalt psychologists, and as always was known on the empirical level for artists).

There are also specific pragmatic features of perceptographic code, which are connected, first of all, with its intention to activate the perceptual level of viewing subject. The perceptography allows to show objects instead of describing them. In contrast to verbal texts, where the plane of contents is developed only on the levels of notions and conceptions, the "mental address" of perceptographic text is just the perceptual level, treated even in narrower sense, - as an ability to construct images of presented forms without identifying and recognizing them (cf. Rock 1985: 105). "Reading" the perceptographic texts supposes interpreter to have different abilities, than for reading the verbal texts - not an ability of pure imagination, but a capacity to construct a perceptive image in the "plane of contents" of lines and colour spots functioning as the "plane of expression". Due to this ability a spectator can see "behind" the painted plane a space of the depicted world. For him the depicted space of the perceptogram can be more or less "transparent". A degree of this "transparency" depends on many pragmatic factors - on a purpose of depiction, on the individual skills of the beholder, on the cultural tradition to use some definite means of perceptography, etc.

The perceptographic code differs not only from linguistic systems but also from other visual-spatial codes, which control the translation of optical information to other mental levels. Particularly, it differs from codes of recognition, which regulate acts of categorization of perceived objects, for instance, - from the object-functional code regulating interpretation of a visible spatial form as a thing with a definite instrumental function (as a hammer, as a pencil, etc.) or from the proxemic code permitting to categorize spatial relations between some people as "close" or "far", "intimate" or "official", etc. The 
codes of this type have features different than perceptual and perceptographic ones do, and due to their structure they are closer to linguistic sign systems. In particular, unlike the perceptographic code, they have a sort of vocabulary — a set of stabile units (visual schemes) used as samples of recognizable forms with invariable meaning, and thereby they are the systems rather of "lexical" than "grammatical" type in the above mentioned sense.

Usage of the perceptographic code provides as a rule conditions for recognition of the depicted objects, as well as - for application of other visual-spatial codes. However the perceptographic code and the codes of recognition are relatively independent from each other. Although the categorization of the visible form can influence the perceptive image, the act of perception (in the narrow sense) is not identical to recognizing of a familiar object and does not need it. The means of perceptography make possible to depict any spatial form independent of its existence, as well as independent of is it recognizable or not. Moreover, even this recognizing does not add any visual details, which can be seen only in the developed perceptive image. On the other hand, as this recognizing is based on the invariant of many of such images, it does not require the development of any of them: the visual categorization of a spatial image is possible even if it is reduced to a simple scheme. For example, a laconic pictogram can be quite a recognizable depiction without forming a detailed picture of object, and at the same time without turning into fully arbitrary sign. So, the pictogram can be considered as a perceptogram, reduced to a minimum set of object's indexes, permitting to use the code of recognition (in contrast to an ideogram, which needs to use this code only for recognizing of itself as a presented sign, but not of any represented object). Something similar one can see also in case of caricature concentrating several recognizable features of person's image without creating a naturalistic portrait.

\section{Perceptography as art}

It is not surprising, that various versions of the perceptographic code develop to the greatest extent in art sphere. Although this code belongs also to other spheres of culture as well, the visual arts involve it in the systems of their expressive and representational means, 
transforming them according to historically changeable norms of its different kinds.

The art at all can be considered as a product of a skilful work with means of some verbal or non-verbal codes, which are used outside of the art sphere too. These codes are not created, but arranged and rearranged in art, which becomes a "laboratory", where the semiotic systems transform and develop most intensively. Diverse kinds of art distinguish between each other with those semiotic systems, which they cultivate, and with the artistic tasks which they put.

In particular, a mastering of different possibilities of perceptographic code is a basis of development of figurative painting and drawing. However, like not all of the said belong to art of word and not all written texts are works of calligraphy, not all of the artificially created depictions are pieces of perceptography as an art. A visual text worked out by means of the perceptographic code gets the quality of art of depiction only if these means and skill of their usage become a subject for special artistic evaluation and satisfies the criteria worked out in an artistic culture.

The art of depiction is not identical to figurative art in general, which uses diverse visual codes. Different kinds of figurative arts painting, drawing or relief - can be considered as arts of depiction as far as they are just the skilful usage and development of various modifications of the perceptographic code. Each of these arts develops its own versions of perceptography for creating the artificial stimuli of perception of objects which are not presented actually. So the painting elaborates a complex of index means for representation of a deep space as, for example, "chiaroscuro" or "aerial perspective". An art of relief uses some perceptographic indices, especially perspective contractions, for volumetric representations (as, for example, in relief of east doors of Baptistery in Florence by L. Ghiberty). A pictorial effect with means of perceptive code can be made even in architecture as for example, it is in the famous "Scala regia" in Vatican, where its creator L. Bernini added to the natural perspective shortening of columns the artificial lessening of distances between them.

The diverse means of perceptography differ also the various ways of depictions in frame one and the same kind of art. In particular, the lineal drawing (for example Villard d'Honnecourd's designs) confines itself only to outlines, representing some borders between forms, and eliminates their tonal and colour "filling". The means of the black- 
and-white graphics (for instance, by Aubrey Beardsley) includes the differences between two polar types of spots, whereas the tonal graphics (as, for example, Rembrandt's engravings) adds more gradations between the dark and the light. The painting obviously uses also the colour diversity and does it in different manner, proceeding from flat "polychromic" to volumetric "colouristic" depictions in various styles and trends.

The treatment to the perceptographic code is of a special stylistic importance for the applied arts, which, on one hand, as a rule hold a task to decorate a surface of useful objects, and, on the other hand, sometimes approaches to the decoration as to a figurative picture. So the difference between two spaces - the depicting and the depicted ones can be in the applied arts more or less strong - from maximum coincidence, for example, in case of flat silhouettes of figures on the surface in classical Greek vase painting, to maximum conflict between them, for example, in the Baroque Age, which was ready "to repeat" the Rafael's or Rubens' pictures on a flat surface of carpet or even to build a depiction of deep and concave space on a convex surface of pottery and porcelain wares. It is a peculiarity of the post-Renaissance artistic and general visual culture - to prefer even in applied and decorative art to look "through" the depicting surface, rather than to look directly at this surface itself.

From this point of view historical development of the arts of depiction, both fine and applied ones, can be treated as diachronic modifications of the perceptographic code: on one hand, - as extension of its means by using new "visual discoveries" (in terms of Gombrich 1960: Ch. IX), and, on the other hand, as more strict their selection. One can find the first step to artificial stimulation of perception in appearance of contours as the means of depictions using in communicative acts already in Palaeolithic Period. The next steps in this direction had permit to depict some spatial relations between the figures due to their coverings and crossings (as in painting of ancient Egypt) or due to representation of depth-relations per height-relations (as in painting of Fern East). There is also the lineal perspective (opened in antiquity and developed by artists of Renaissance) in the same row of "visual discoveries". One can see, how the dominating elements of the perceptographic code have changed from lineal to tonal and colour ones: the "graphic" outlines of depicted figures (in ancient and medieval painting) were changed by depictions of 
"sculptural" volumes due to using of light and shadow (in painting of the Renaissance), then - by "architectural" constructions of complex built space by means of linear and aerial perspective (especially, in the Baroque paintings) and again - by painted "dissolution" of depicted forms and their local colours in a vague milieu of many divided chromatic elements (in the paintings of Impressionists).

The art of perceptography develops not only as a skill to create perceptive images of absent objects, but also as a skill to direct the process of perceiving. An artist constructs the relations of lines and colours in a depicting space in such way, that they visually unify something one and separate something other, singling out more important details and taking away secondary ones, etc. Skilful usage of perceptographic means by an artist can at first attract viewer's attention to one part of a picture, lead his look in a definite direction, at the same time "hiding" some other details of the picture till the next stage of the process of perception. So, for example, the elders from Tintoretto's "Susanna and the Elders" (Kunsthistorisches Museum, Vienna) are hidden in the bushes not only from Susanna, but also, till definite moment, from viewer's look. This skill to lead a look in a definite succession can be considered semiotically as the know-how to arrange the visual signals controlling the process of looking into the picture.

Mastering the means of the perceptographic code leads to historical changes of "forms of vision" and relations between the perceptographic and other visual-spatial codes. For example the perceptographic code in icon painting had to perform rather secondary function and was of less importance for Medieval visual culture, than, let us say, iconographic code, which connects the perceived and recognized figures with some verbal interpretations, first of all from the Sacred Book. However the later cultural transformations and secularization of the European culture were revealed in the sphere of visual culture particularly through the change of relations between the perceptographic and iconographic codes. The Renaissance, Baroque and Impressionists' paintings can be considered as the successive stages of increasing role of the perceptographic code in visual culture and its releasing from the subordination to the iconographic and other codes.

The perceptographic code was interesting for diverse epochs with its different possibilities. If mastering its means for the Renaissance 
and Baroque artists was connected with the skill to make a depicting surface "hidden" from a spectator and "transparent" for the depicted world, the artists of the later epochs gave up the attempts to create an illusion of its absence, but, on the contrary, drew attention to the depicting plane. Particularly, in Impressionists' and Post-impressionists' paintings it became less "transparent", delaying a "transit" of the look into a depicted space and attracting the sight to lineal and colour elements on the surface. In the Cubists' paintings composition of these elements on the depicting plane becomes more important than the depicted objects. The Abstract art performs the next step: the lines and colour spots on the surface are independent of the function creating perceptive image of the depicted space. Thereby the perceptographic code turns out beyond the artistic attention, making way for the synesthetic, architectonic and other visual codes, which do not need to use perceptography. In the same time this change has eliminate from painting a complex of spatial codes, usage of which depends on creating depictions: body-language, mimic, proxemic, objectfunctional, social-symbolic, etc.

\section{Perceptography and external optical means}

Transformations of the perceptographic code in culture are connected with the changes of the external technical means used for creation, transmission and reception of visual images of space. Each of them transmits and transforms these images in its own way and introduces a possibility of some new "forms of vision" in visual culture.

In particular, usage of lineal contours for representation of depicted objects indeed depends on possibilities, which the culture gives (as it was suggested by Eco 1976: 194). However the cultural "graphic conventions" do not create absolutely arbitrary signs, but representative means motivated by the ability to abstract and to exteriorize the borders between different patches in a visual field. This ability and corresponding "conventions" are connected with the development of ways of drawing and engraving of lines on a surface, which were known in culture since the Upper Palaeolithic Period. The development of the "architecture with regular courses of jointed masonry", as it was mentioned by Meyer Schapiro, prepared the appearance of the "regular field" of depiction (Schapiro 1994: 3). Modifications of 
"graphic forms of vision" can be correlated with such technical inventions as fresco, mosaic, encaustic, glaze, etching, etc. Invention of the oil paints and the change of palette function (as a tool not only for a rubbing but also for mixing paints) promoted a development of the "painting way of vision" and created conditions for the establishment of the "principle of palette" for the perceptographic code of the NewEuropean painting.

In a row of technical means elaborated in culture for operating optical processes, a painted picture can be understood as an instrument, comparable with such technical inventions as mirrors, stainedglass or transparent windows, lenses, etc. Each of these technical means together with its possibilities of optical transformation gives opportunities of some own ways of vision. If, for instance, the medieval stained-glass windows permitted to show the depicted figures as immaterial ideas "floating" in the rays of light, the transparent windows, on the contrary, help to see an earthly "picture" behind their frame. The development of transparent windows since the Renaissance Age, as well as of glass mirrors (often having a form of windows) made a contribution to construction of linear perspective. Besides, a mirror allows the subject to see himself as an external object, and spreading of glass mirrors was a condition for the development of self-portrait paintings and for reflections over the relations between the painter and the model ("The Arnolfini Marriage" by Jan Van Eyck, "Las Meninas" by Velazquez, etc.). In a similar way the production of lenses and "magnifying glasses" influenced the wish to peer into small details, and it is notable, that Leeuwenhoek's discoveries coincide with the "golden age" of still-life in Dutch paintings, where the optical instruments were used for creating the naturalistic illusion.

When photography, based on combining of lenses and lightsensitive materials, was developed, the ways of vision changed again. These technical means of optical representation changed a valuation of traditional means of depiction. The "depressing perfection" (as E. Delacroix said) of mechanical means of depiction deprived former ways of the artificial stimulating of perception its high cultural status and removed them from centre to periphery of art culture. The new means of depiction change ways of representation of space and time in the picture. Instead of the relatively complete and closed model of the world, which was created in classic picture and, especially, in 
medieval icon painting, photography due to its technology has to fix only single fragments of the spatial world. It does not "collect" the features of different things in one image - as painting do, but takes only something partial, concrete and individual. Therefore, it reproduces the space of the world not metaphorically, but metonymically. The change in the ways of vision after developing of photography influenced the painting itself, which began purposely "cut" a depicted space and represent it as a fragment of space exceeding the frames of a picture (for example, in Degas' paintings).

Cinematography extends this depicted space even more, "linking" many photograms in time and synthesizing its single fragments in discrete or continual rows. Thereby a new "cinematographic" way of vision was developed and influenced new forms of perceptography in paintings. Painters began looking for the means of division of spatial movement into single stages and their "summarizing" in a united picture (especially this way of vision was developed by Futurists).

As a continuation of the row of technical means creating depictions like photography and cinematography a "computerography" can also be considered. It allows to combine depicted spaces of different kinds, to join and to separate them, change their metric and topologic properties, etc. Despite each of these technical opportunities are known long ago to artists separately, their combination by computer gives more freedom for visual thinking.

However, the "photograms" differ from "chirograms" (in Gibson's terms) not only regarding to hand-created, but also to "mind-created" product of artist. They are not "perceptograms" in full sense, because they do not exteriorise a perceptive image of any subject more, but remake only optical conditions of its receiving. A "mechanical" reproduction of such conditions permits the spectator to master only the means of the natural (as far as it is possible for culturally educated mind) perceptual code, and not to develop special skills of perceptograms "reading". Nevertheless an artistic application of perceptography in these "photograms" is possible in case the picture is specially constructed as if it was made by the hand and mind of an artist - as, for example, in case of Sergey Eisenstein, who drew the single frames of his future films as artistically ordered pictures.

So, the connection between the external optical technique and the "internal implements" mediating the "technique of vision" in the perceptographic and other visual codes is obvious. Both of them 
develop according to their own "logic" and are also determined by the conditions of the visual culture. If the last is not ready yet to accept some visual ideas, only technical possibilities for their realization are not enough. For example, despite the mosaic technique gives possibility for optical mixing of colours and for the "alphabetic" principle of their arrangement, only Pointilists, based on the "irrelevant" technique of oil paintings, treated to these means as to the subject of special artistic elaboration.

\section{Some methodological remarks}

Semiotics of visual-spatial codes and especially semiotics of perceptography is a sphere, where an application of traditional semiotic conceptions comes across with a "resistance" of the researched material. It is not surprising, because the main versions of semiotics are based on generalizations of verbal and derived from them sign systems - in the spheres of logic (Peirce and others) or linguistics (Saussure and followers). Both of them deal with higher levels of mental activity operating more or less abstract conceptions and generalized ideas. Despite the visual-spatial means of representation afford to express such conceptual meanings as well, much of them are formed on lower levels of mind. It is true for the synesthetic codes, mediating connections between feelings of diverse modalities on the sensory level, particularly - for the architectonic code, regulating relations between visual images and kinaesthetic feelings of mechanical forces, of weight relations, of balance, etc. It is true also for the perceptual and derivative perceptographic codes, which plane of contents is developed on the perceptual level. The codes mediating connections on these levels belong themselves to the index-signal type of information processes and are not sign-codes, if the concept of "sign" is accepted in enough narrow sense (see Tchertov 1999). These "nonsign" means of communication can remain nevertheless in the sphere of semiotic, if the last is not limited by linguistic or logic projects and is extended to all code means of information generating in culture or in nature as well. Such broad treatment of "semiosphere" allows not only to include natural index-signal systems in the frame of semiotics, but also to consider in these frame some transformations, which are occurred with many of these codes in culture. 
The codes generating in the nature and transforming in a visual culture are a common subject matter, particularly, for psychology of human, where from time of G. Berkeley develops an idea of "visual language". The great interest to semiotics of visual-spatial means has also aesthetics, which by its separation in Baumgarten's work has already provided "Semiotica" as its necessary part (Baumgarten 1750: $\S 13$ ), and which is, following Croce, an "universal science of expression". One can find many of "protosemiotic" ideas in art theory, which from L. Alberti till E. Gombrich researches the means of visual representation. It is naturally therefore that researches into sphere of art or into psychology of visual perception are included in context of the pictorial semiotics (as, particularly, in Sonesson 1992; 1995). In the same time it is also true, that semiotics of the visual-spatial codes in general, and semiotics of perceptography, specifically, is not identical to conceptions of psychologists, aesthetists or art theorists. Their fruitful ideas can be developed and get more exact explication within domain of these branches of semiotics. However it is possible only under the condition, that a pertinent set of concepts will be elaborated in the sphere of visual semiotics itself. The presented paper is an attempt to do some steps in this direction.

\section{References}

Baumgarten, Alexander 1961 [1750]. Aesthetika. Hildesheim: Georg Olms Verlagbuchhandlung.

Bruner, Jerome S. 1973. On perceptual readiness. In: Bruner, Jerome S., Beyond the Information Given. Studies of the Psychology of Knowing. New York: Norton \& Co: 7-42.

Bühler, Karl 1934. Sprachtheorie. Die Darstellungsfunktion der Sprache. Jena: Fischer.

Eco, Umberto 1976. A Theory of Semiotics. Bloomington: Indiana University Press.

Gibson, James 1950. The Perception of the Visual World. Boston: Houghton Miffin Company.

- 1979. The Ecological Approach to Visual Perception. Boston: Houghton Mifflin Company.

- 1980. Foreword: A prefatory essay on the perception of surfaces versus perception of markings on a surface. In: Hagen, Margaret A. (ed.), The Perception of Pictures. Vol. 1. Alberti's Window: The Projective Model of Pictorial Information. New York: Academic Press: xi-xvii. 
Gombrich, Ernst 1960. Art and Illusion: A Study in the Psychology of the Pictorial Representation. (Bollingen series XXXV.) New York: Pantheon Books.

Goodman, Nelson 1968. Languages of Art: An Approach to a Theory of Symbols. Indianapolis: Bobbs-Merill.

Gregory, Richard 1970. The Intelligent Eye. London: Wienfeld and Nicolson.

Hartmann, Nicolai 1953. Ästhetik. Berlin: Walter de Gruyter \& Co.

Hildebrand, Adolf von 1988. Gesammelte Schriften zur Kunst. Opladen: Westdeutscher Verlag.

Kapp, Ernst 1877. Grundlinien einer Philosophie der Technik: Zur Entstehungsgeschichte der Cultur unter neuen Gesichtspunkten. Braunschweig: Westermann.

Panofsky, Erwin 1998. Die Perspective als “symbolische Form”. In: Panofsky, Erwin, Deutschsprachige Aufsätze II. Berlin: Akademie Verlag: 664-757.

Rock, Irvin 1985. Wahrnehmung: von visuellen Reiz zum Sehen und Erkennen. Heidelberg: Spektrum der Wissenschaft Verlag.

Saussure, Ferdinand de 1972. Cours de linguistique générale. Edition critique prepare par Tullio de Mauro. Paris: Payot.

Sedgwick, Harold 1980. The geometry of spatial layout in pictorial representation. In: Hagen, Margaret A. (ed.), The Perception of Pictures. Vol. 1. Alberti's Window: The Projective Model of Pictorial Information. New York: Academic Press: 33-90.

Schapiro, Meyer 1994. On some problems in the semiotics of visual art: Field and vehicle in image-signs. In: Schapiro, Meyer, Selected Papers. V. 4. Theory and Philosophy of Art: style, Artist, and Society. New York: George Braziller: $1-32$.

Sonesson, Göran 1992. The semiotic function and the genesis of pictorial meaning. In: Tarasti, Eero (ed.), Center and Periphery in Representations and Institutions. (Proceedings from the ISI Conference in Imatra, July 16-21, 1990. Acta Semiotica Fennica.) Imatra, 221-256.

- 1995. On pictorality: The impact of the perceptual model in the development of pictorial semiotics. In: Sebeok, Thomas A.; Umiker-Sebeok, Jean (eds.), Advances in Visual Semiotics. Berlin: Mouton de Gruyter, 67-105.

Tchertov, Leonid 1999 = Čertov, Leonid. The sign prism: A spatial model of semiosis. European Journal for Semiotic Studies 11(1-3): 57-73.

Wölfflin, Heinrich 1956. Kunstgeschichtliche Grundbegriffe. Das Problem der Stilentwicklung in der Neueren Kunst. (11. Aufl.) Basel: Schwabe \& Co. AG Verlag.

\section{Перцептографический код в визуальной культуре}

Визуальная культура может рассматриваться с семиотической точки зрения как система визуальных кодов. Некоторые из них имеют еще естественные корни. Так, перцептивный код формируется уже на биологическом уровне, опосредуя превращение сенсорных данных в перцептивные образы пространственного мира. Средства естествен- 
ного перцептивного кода трансформируются в культуре, включаясь в процессы коммуникации с помощью изображений. Изображение на плоскости может рассматриваться как “перцептограмма”, которая представляет собой, с одной стороны, внешнюю запись какого-то внутреннего перцептивного образа или представления, а, с другой стороны, - программу, в соответствии с которой строится визуальное восприятие зрителя. Средства такой перцептографии образуют уже некий искусственный код, который, в отличие от естественного перцептуального кода, оказывается коммуникативным, произвольно используемым и изменяющимся различным образом в разные периоды времени, в разных видах практической и художественной деятельности. Не всякая перцептограмма становится произведением искусства, однако вся история искусств может быть рассмотрена как процесс овладения этими средствами и их развития. Этот процесс зависит как от внутреннего изменения "форм видения", так и от создания новых внешних средств коммуникации.

\section{Pertseptograafiline kood visuaalkultuuris}

Visuaalkultuuri võib semiootiliselt vaatepunktilt vaadelda kui visuaalsete koodide süsteemi. Mõned neist lähtuvad veel loodusmaailmast. Nii näiteks formeerub pertseptiivne kood juba bioloogilisel tasandil, vahendades sensoorsete andmete muutumist ruumilise maailma pertseptiivseteks kujunditeks. Loomuliku pertseptiivse koodi vahendid transformeeruvad kultuuris, lülitudes kommunikatsiooniprotsessidesse kujutiste abil. Kahemõõtmelist kujutist võib vaadelda kui "pertseptogrammi”, mis kujutab endast, ühelt poolt, mingi sisemise pertseptiivse kujundi või ettekujutuse ülestähendust, teisalt - programmi, millele vastavalt ehitatakse üles vaataja visuaalne vastuvõtt. Taolise pertseptograafia vahendid moodustavad juba teatud kunstliku koodi, mis, erinevalt loomulikust pertseptiivsest koodist, osutub kommunikatiivseks, mida vabalt kasutatakse ja muudetakse erinevatel aegadel, erinevates praktilise ja kunstilise tegevuse sfäärides. Mitte iga pertseptogramm ei saa kunstiteoseks, kuid kogu kunstiajalugu võib vaadelda kui nende vahendite omandamist ja arendamist. See protsess sõltub nii "nägemise vormide" sisemisest arengust kui ka uute väliste kommunikatsioonivahendite loomisest. 